\title{
Implementing Ecolinguistics Approach to English as a Foreign Language (EFL ) Course Design for Raising Environmental Awareness
}

\section{preparation}

Haggag Mohamed Haggag (PhD)

South Valley University, Hurghada Faculty of Education, ELT

Department, Red Sea, Egypt

DOI : $10.12816 / 0051210$

مجلة الدراسات التربوية والانسانية ـ كلية التربية ـ جامعة دمنهور .

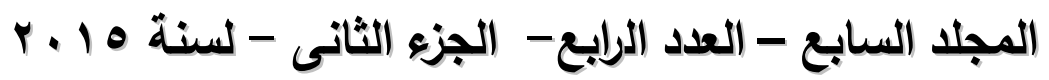


Implementing Ecolinguistics Approach to English as a Foreign Language (EFL) Haggag Mohamed Haggag 


\title{
Implementing Ecolinguistics Approach to English as a Foreign Language (EFL) Course Design for Raising Environmental Awareness
}

Haggag Mohamed Haggag $(\mathrm{PhD})$

\begin{abstract}
This paper discusses the theory and the practice of introducing a fairly new branch in linguistics into English as a Foreign Language EFL course design to raise students' environmental awareness. In a descriptive analytical method, the paper has three purposes; the first is to introduce Ecolinguistics as a language discipline and as a course design approach. The second is to show how this approach can be integrated in EFL course design models giving MHRAN model as an example. The third is to relate the environmental awareness to course design models. The theoretical framework includes Ecolinguistics approach to EFL course design and the environmental awareness aspects while the practical part includes teacher's needs analysis and student's environmental awareness questionnaires. Results of the analysis are discussed as well as the recommendations.
\end{abstract}

Key words: Environmental Awareness, Ecolinguistics, TEFL and Course design

\section{Introduction:}

Ecolinguistics or the ecology of language is the study of language in ecological contexts (Feng \& Fan (2012), Wiertlewska (2011), Hugen (2001)). This respectively new branch of language is important in this global-based education. Educational systems prepare their students to live not only for their own or their communities but for the world. From this global perspective, this paper calls for a national trend in language teaching in Egypt that integrates Ecolinguistics as a growing field of linguistics in the English language courses. Course design models should integrate Ecolinguistics during the process of design. This assures the planning for language learning and guarantees set roles for the students, teachers and assessment. One of the models suggested by the researcher is MHRAN model that can be used for such a purpose. This model with its layers - as will be described- can show the input, processes and outputs of Ecolinguistics integration in EFL courses. 
Raising the environmental awareness which refers to "the sensitivity to the total environment and its allied problems" (Sengputa, et al. (2005, p.5) is one of the purposes behind this integration. Students can develop their language skills from the one hand and can be aware of their environment from the other. This notion copes with world education trends considering that the United Nations UN has designated the period 2005-2014 as the decade of education for sustainable development (UNESCO, 2007). Such trend in language education can help students to be good citizens and to have positive impact on their societies.

According to Van Lier (2004, p.5): This integration underpins six concepts: 1. Relations, if we see language as a system of relations. 2 . Context, since it is not only surrounding language and defining it but also being defined by it. 3. Patterns and systems; viewing language as a pattern of patterns and a system of systems. 4. Emergence; language is not a linear acquisition but as emergence. 5. Diversity as essential in an Ecosystem. 6. Activity; language is activity and emerges out of activity. The suggested model (MHRAN) considers the above restrictions and views of Ecolinguistics in EFL courses.

Based on the above considerations, this paper suggests a model to implement Ecolinguistics in English language courses in Egypt to develop students' environmental awareness. The main question that the paper seeks to answer is how to integrate Ecolinguistics in EFL courses to develop students' environmental awareness. To answer this question, a descriptive analytical method has been used to cover the theoretical framework and the experimental part.

\section{Theoretical framework:}

Language is a human activity that aims at communication. From this perspective language teaching and learning target a major objective which is communication. There has been a vast development in the different fields of language, its academia and pedagogy. One of the recent fields in language is Ecolinguistics which was first introduced (Lecheverel : 2009) in a book entitled Endangered Languages in 1999 although others as (Wiertlewska, 2011) date it to the Norwegian linguist Einar Haugen in 1972 . Ecolinguistics, ecology of language or language ecology has been early defined by Hugen $(2001$, p.57) as "the study of interactions between any given language and its environment". Similarly, Muhlhausler \& Peace $(2006$, 68) defined the ecology of language as "the study of interactions between any given language and its cultural and political environment". Further definitions (i.e. Mufwene 
(2001) and Wendel (2005) extended the scope of Ecolinguistics to describe language problems in a sociolinguistic, political, economic and educational settings. Feng \& Fan $(2012,1)$ view Ecolinguistics as a new branch of linguistic study which aims at the following:

To investigate the role of language in the development, and the possible solution of ecological and environmental problems. It combines the study of ecology and the study of Linguistics. The range of Ecolinguistic is wide, which includes linguistic diversity, environment of the language system, ecological criticism, language acquisition, language planning, and language policy and so on.

The theory and practice behind this growing field can be identified from what Alwin Fill's (2000, p.1) description of Ecolinguistics as follows:

Ecolinguistics criticize language in the levels of language and parole and point out un-ecological language uses and "anthropocentrism" which present nature from the point of view of its usefulness on humans. In a wider understanding, the "growthism", "sexism" and "anthropocentrism" inherent I many languages and language uses are criticized. Another important field of Ecolinguistics is the research area of the relation between linguistic and biological diversity (two phenomena ecolinguists aim to preserve.

Based on the previous review of definitions and scope of Ecolinguistics, this paper sheds the light on how to integrate this growing field in English as a foreign language EFL course design and thus language learning. Language acquisition is one of the fields that are connected to linguistics in general and therefore Ecolinguistics. A question such as how to use the terms and concepts related to environment in learning the language has been significant. The answer of this question is in the various types of courses, activities and language exercises that can use these concepts related to ecology in language acquisition. The objective behind these practices is not only linguistic awareness but also for improving or raising the environmental awareness in various language discourses.

Muhlhausler (2003, p.2) identified the relation between Ecolinguistic study and discourses in the following four main areas: 
- Language is for cognition: it exists in a social and environmental vacuum (Chomsky).

- Language is constructed by the world (Marr).

- The world is constructed by language (structuralism, poststructuralist).

- Language is interconnected with the world. It both constructs and is constructed by it (Ecolinguistics).

The above four areas of Ecolinguistics cover the innateness of language or how to acquire the language as an innate component and how to structure it in relation to context. These four views of Ecolinguistics should form the theoretical basis of the English language courses that include Ecolinguistics.

\section{Course design and Ecolinguistics:}

This paper attempts to integrate Ecolinguistics as a growing linguistic discipline in EFL course design. This can be carried out in the different stages of course design, the teaching procedures and in the assessment. One of the models that can highlight this integration is the Multi Harmonized Resources and Needs (MHRAN) model by the researcher. This model was introduced by the researcher in 2013 as part of his dissertation theory in Karl-Franzens University. This model adds 3 layers; the evaluation, the procedures and the integration layers, thus, it integrates four layers that can describe the different communicative based processes of course design, communicative teaching and communicative testing. The model encompasses Multi Harmonized Resources and Needs, therefore the researcher names it MHRAN model for communicative course design, teaching and testing. At the bottom of the model, four different layers are shown as the following figure (1) shows. 
Figure (1.): MHRAN Model for communicative course design, teaching and testing

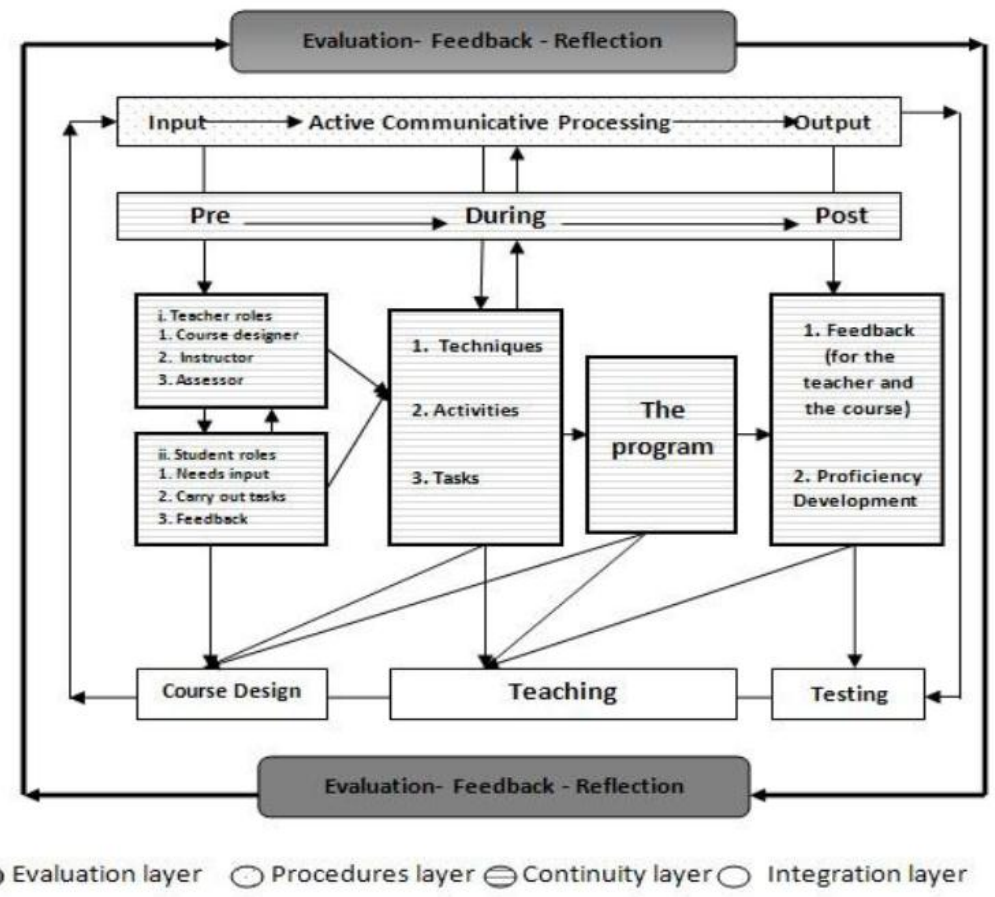

MHRAN model proposes a communicative integrative view of EFL course design, teaching and testing. The model is a description for a comprehensive system that intervenes three main communicative elements which are course design, teaching and testing. The aim behind the model is to state and to describe the communicative processes that guide and link course design, teaching and assessment. The model may overcome the gaps- as viewed by the researcher- between these three interrelated areas.

As to the four layers of the model: the first layer-black layerencompasses three processes: evaluation, feedback and reflection. These three process aim at assessing, providing suggestions and insights for solving the different problems and obstacles in an integrated system of course design, teaching and assessment. This layer encompasses all the processes in the system in its pre, during and post stages. It integrates the input and output by the student and the teacher in the course design, teaching and testing. Evaluation is for the materials, assessment tools, teaching techniques, results of tests and activities; it is a pre, during and 
post-process that ensures that the course, the teaching practices and the test match the communicative setting of learning the language.

Feedback is provided by both the student and the teacher during the learning cycle. The students provide feedback about the course, activities and teaching techniques of the teacher. The teachers provide feedback about their own expectations of the course, its techniques, topics and class organization. Teachers provide feedback to the students regarding their learning and communicate with them to solve their problems and to track their progress. Reflection too is done by the student and the teacher; the students present their view of their learning and their learning strategies. They reflect on their successes and problems during the activities which provide chances and various spaces for reflection.

The three processes of evaluation, feedback and reflection provide suggestions and help both the course designer and the teacher in carrying out the different improvements that enhance the language course, the teaching practices and the testing procedures. In this stage, pre testing is a requirement to track the development that occurs in the students $^{\text {ee }}$ performance when compared with the post testing. The second layer -the dotted layer-describes the processes layer in the model. The Processes include three procedures that guide the course design and teaching, and consequently affect the testing procedures.

These three processes are the input, the communicative processing and the output. They are interrelated and bounded by continuous evaluation, feedback and reflection as shown in the evaluation layer. The Input refers to the different language areas in the course. From the teaching perspective, input is the integrated English language skills to be instructed in a communicative course. From the course design perspective, input refers to the tools, questionnaires and reflective ideas that form the bases of the course. The teacher and the student are the main input providers in this stage. This input is a main component in the design of the test objectives in a following summative evaluation process. Testing in this model starts from the communicative input of the course; aims of the language test should stem from the input given by the student and the teacher in the first place.

The Active Communicative Processing refers to the implication of CLT in the design and the teaching of the language course. These processes include active learning-based techniques that promote the communication between the students, which will be discussed in the continuity layer. This layer describes the design of the activities and tasks using techniques that are determined in the input stage. This linear

DOI : $10.12816 / 0051210$ 
view of input, processing and output leads to the following sequential layer. The third layer - the striped layer -describes the realization of the first and the second layer since it describes the form of actual input, aspects of the active communicative processing and the form of the output. Pre refers to the different roles played by the teacher and the student in the course design, teaching and testing. It refers to the teacher as course designer, instructor and assessor.

The student provides input by stating his needs and expectations from the course and the instruction, which should allow him to take responsibility of his own learning and to communicate actively. Carrying out the tasks and activities and providing feedback are other important roles by the student in this stage. During refers to techniques, activities and tasks that were determined in the pre stage and that form the course or the program. In a course perspective, during phase represent the actual making of the course with its activities and tasks. In a teaching view, during phase refers to the teaching practices of the teacher and the instruction procedures using active learning techniques that allow the student to communicate actively. Summing-up, during refers to the actual design of the activities from a course design view, teaching them communicatively from a teaching view and carrying out formative assessment from an assessment view. Post refers to the feedback and the summative evaluation for the language proficiency. These two procedures relate to the course design, teaching and testing. In the course design view, post means to generate feedback from the students and the teachers about the course and its activities. From the teaching view, the teacher generates feedback about his teaching procedures and provides summative conclusions and revisions. From an assessment view, post refers to the summative testing from the one hand and to the formative feedback for both the course and teaching procedures. In this stage, post testing that covers the four language skills is a major requirement.

The fourth layer - the white layer- is the integration layer. It shows the integration between the course design, teaching and testing. The reflection and feedback of the first layer, the input of the second layer and pre-components of the third layer are represented in the course design of the fourth layer. Evaluation, feedback and reflection of the first layer, active communicative processing of the second layer, and during of the third layer are represented in the teaching of the fourth layer. Evaluation, feedback and reflection of the first layer as well as output of the second layer and post of the continuity layer are represented in the testing of the fourth layer. Language testing in this view encompasses the four language skills. 
These three areas are interrelated and affecting each other in a communicative system. Summing-up, the Multi Harmonized Resources and Needs MHRAN model is a course design, teaching and assessment model that are intervened in four layers. These four layers are the evaluation layer, the procedures layer, the continuity layer and the integrated layer.

\section{Integration of Ecolinguistics in the model:}

As the model suggests, input, processes and output are the key pillars to integrate Ecolinguistics in language teaching. In the input layer, teachers and course designers should select appropriate graded texts and exercises to use the language in environmentally-based contexts. This can be handled in the reading passages, conversations, and the four language skills (listening, speaking, reading and writing). The processes layer includes how to involve and share the texts in a communicativebased teaching in the class. Students as well as teachers should target "communication" in the first place (Newby, 2011). In the output layer, students should provide feedback to the teachers about their knowledge, skills and attitudes about this integration of Ecolinguistics to their language courses. As to assessment, both assessments for learning and of learning should be included in this integration.

\section{Environmental awareness:}

Sengupta et al. $(2010,5)$ view the environmental awareness to mean "the sensitivity to the total environment and its allied problems. The development of environmental awareness means to understand the environmental problems and to develop critical thinking and problemsolving skill in the people." This awareness is essential for world education and particularly in the developing countries like Egypt. Shoukry et al. $(2012$, 1) highlight this educational requirement "environmental issues such as environmental attitudes are important socio-environmental subjects for the non-western countries such as Egypt". In their study about the level of environmental awareness in Egypt, low levels were obtained and overall percentage mean scores $23.8 \% \pm 33.2 \%$ which clearly show the very low percent. This percent is for $78.9 \%$ of the participants who showed low levels of awareness to environmental laws and guidelines.

Education plays a key role in raising environmental awareness and good environment related knowledge, skills and attitudes. Hoerisch (2002,

DOI : $10.12816 / 0051210$ 
22) analyzes the different factors that influence the environmental awareness to the following:

Unemployment was considered to be a more serious problem by $71 \%$, insufficient education by $66 \%$ and poverty by $52 \%$, while $39 \%$ thought of crime, $37 \%$ of corruption and $22 \%$ of religious or social conflicts as more urgent problems to be tackled than environmental pollution.

The role of education is significant as the survey shows $(66 \%$ of the participants) and therefore courses should aim at raising the environmental awareness and therefore English language courses with their inter-and-intra cultural aims should serve such a purpose. From this perspective, a growing field of education named Environmental Education was evolving. Frontier et al. (1998, p.11) states that the Wisconsin Environmental Education Board (WEEB) defines environmental education to mean:

A lifelong learning process that leads to an informed and involved citizenry having the creative problemsolving skills, scientific and social literacy, ethical awareness and sensitivity for the relationship between humans and the environment, and commitment to engage in responsible individual and cooperative actions. By these actions, environmentally literate citizens will help ensure an ecologically and economically sustainable environment.

Environmental education should help the students to be aware of their environments and environment-related issues. It should aim at helping the students to think globally and act locally. To achieve such a goal, English language courses should combine activities and drills that develop the language skills using Ecology-based texts. These texts will serve a dual purpose to develop the English language and to develop students' environmental awareness.

\section{Instruments and materials:}

This paper utilizes two questionnaires by the researcher: (a) Students' environmental awareness questionnaire and (2) teacher needs analysis questionnaire. The link to the questionnaires is \{https://www.surveymonkey.com/summary/_2BryDZ16E5zehxh6Ny5u 4leIciwdeMqN8BipKRkpTOKM_3D\}. Both the questionnaires were run online through "Survey Monkey" website. The two questionnaires aimed at analyzing the participants' awareness to Ecolinguistics and 
measuring their attitudes towards English language courses that cover environment-related texts and language activities. Participants were (35) English language teachers from Red Sea governorate and (40) students from the same governorate in different prep stage schools. The two questionnaires included the following main elements: a. Bio-data b. Language related questions and c. Environmental awareness related questions. The participants (N. 110) had to respond to the questions and submit them to the researchers email. Analysis for the responses was run using quantitative and qualitative analysis as follows.

\section{Results:}

Results of the teacher needs assessment questionnaire for the key questions (see appendix) show the following results:
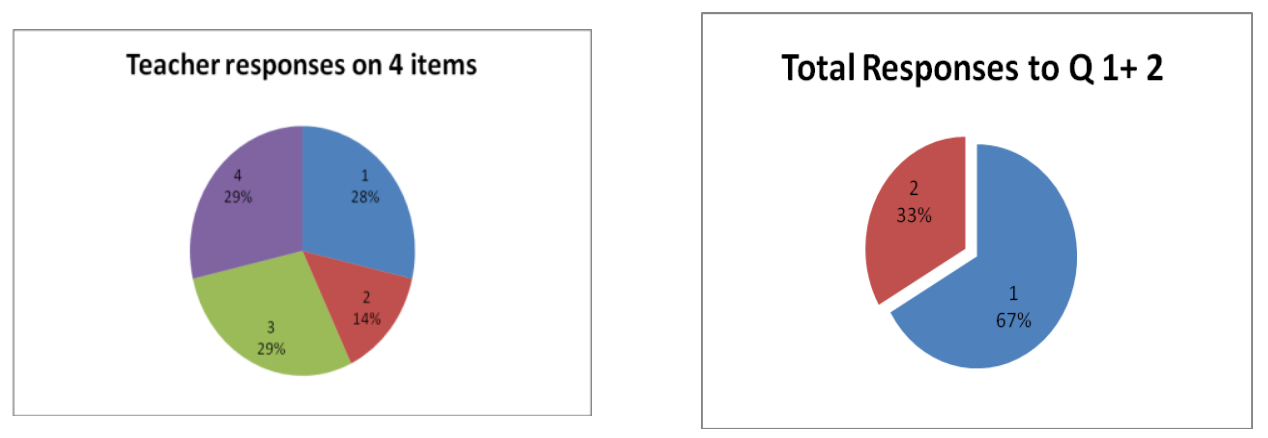

Results of the teacher questionnaire indicate that (29\%) of the teachers think that the courses they teach cover environmentally-related texts while $(86 \%)$ of them are not aware of the term Ecolinguistics. Only $(29 \%)$ of the teachers think that English courses should include environment-related courses while (29\%) of them view that Ecolinguistics should be integrated in teaching the four language skills. Analyzing the results shows that most of the English language participants are not even aware of Ecolinguistics as a language discipline. Results also showed that the total responses to questions 3 and 4 were the following: $67 \%$ of the participants view that environment related texts can be integrated in language teaching and assessment and $33 \%$ of the participants view that course design, teaching and assessment can include Ecolinguistics discipline. 
As to the student online questionnaire for environmental awareness, the following results for the four main questions were obtained:

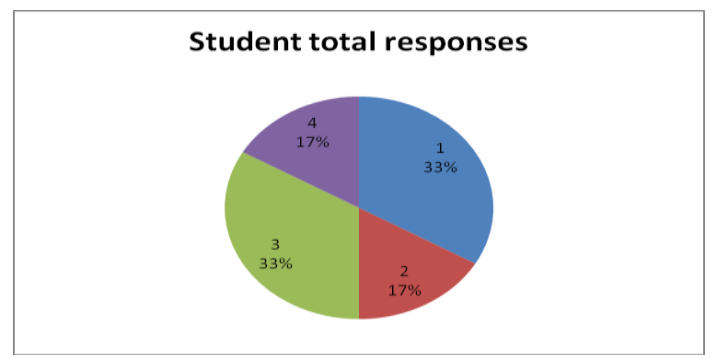

Responses to tuc ins yucsuvin siuw una language courses should contain texts related to the environment. Exams should contain texts about the environment as approved by only $17 \%$ of the participants. This low percent can be attributed to the respectively new discipline and to the use of assessment in Egypt as a summative assessment. $33 \%$ of the students stated that they have studied environment related texts in English course books. As to the fourth question about the global environmental problems awareness, only $17 \%$ of them stated that they are aware of these problems and could state some.

In sum, both teachers and students stated that they have taught or studied texts related to environment; this means that environmental concepts and language are not new to the field of language learning. Teachers and students share concerns about integrating Ecolinguistics in some forms of assessment and mainly summative ones. Most of the English language teachers in Egypt are not aware of the term Ecolinguistics due to the respectively new emergence in language learning. Participants could not propose a clear model that designates courses, teaching and assessment to Ecolinguistics. 


\section{Recommendations:}

This paper recommends a model (MHRAN) that can be used in English language course design, teaching and assessment of Ecolinguistics in EFL classes. Training to both teachers and course designers should be carried out to integrate new disciplines to language teaching such as Ecolinguistics. Linguists, academics, ecologists, course designers, teachers and students should cooperate in designing language courses that integrate Ecolinguistics communicatively. Assessment of learning and for learning should be considered in teaching Ecolinguistics courses. 


\section{References}

1. Feng, R., Fan, A. (2012). A brief analysis on the lettered words in Chinese from the perspective of Ecolinguistics. IERI Procedia, 2 (12)

2. Fill A. \& Mulhauser, P. (2001) .The Ecolinguistic reader. Language, Ecology and Environment. London : Continuum

3. Fortier, J., Grady, S., Lee, S., Mrinac, P. (1998). Wisconsin's model academic standards for environmental education. Bulletin 9001. Wisconsin publications

4. Haggag, M. (2013). A suggested program based on active learning to develop TOEFL-iBt-oriented language proficiency of nonEnglish specialized researchers. Dissertation, Graz University, Austria

5. Haugen, F. (1972). The Ecology of language. Essay by Einar Haugen. London: Stanford University press

6. Hoerisch, H. (2002). A comparative study on environmental awareness and environmentally beneficial behavior in India. Center for Media Studies. New Delhi, India

7. Lechevrel, N. (2009). The intertwined histories of Ecolinguistics and Ecological approaches of languages(s). Symposium on Ecolinguistics. University of Southern Denmark, Odense Institute of language communication

8. Mufwene, S. (2001). The Ecology of Language Evolution. Cambridge University Press Sengupta, M., Das, J. and Maji, K. (2010). Environmental Awareness and Environment Related Behavior of Twelfth Grade Students in Kolkata: Effects of Stream and Gender. Anwesa Journal, Vol. 5 (8)

9. Newby, D. (2006) 'Communicative Language Teaching'. In Fenner, A.B. and Newby, D. (eds.) Coherence of principles, cohesion of competences: Exploring theories and designing materials for teacher education. Graz/Strasbourg: European Centre for Modern Languages/Council of Europe Press, p.17-26.

10.

houkry, S., Saad, S., El Temsahi, S. and Abolfotouh, M. (2012). Toward the Environment Awareness, Attitude, and Concerns of Workers and Stakeholders of an Environmental Organization. Available online: DOI: 10.1177/2158244012462223

11.

ESCO, (2007). The UN decade of education for sustainable development. Retrieved from: www.unesco.org/education/desd $\{14.07 .2014\}$ 
12.

an Lier, L. (2004). The Semiotics and Ecology of language learning. Journal of Utbilding \& Demokratis, 13(3), pp. 79-103

13. Wiertlewska, J. (2011). Ecolinguistic approach to foreign language teaching on the example of English. Adam Mickiewicz University Press: Poznan 